\title{
Strategies for maintaining and improving clinical credibility of nursing lecturers: A meta-synthesis study
}

parvaneh soodmand ( $\nabla$ soodmand1894@mshdiau.ac.ir)

islamic azad university mashhad medical sciences university

Seyyed Mostafa Mohsenizadeh

Birjand University of Medical Sciences

Ali Meshkinyazd

Mashhad University of Medical Sciences

abolfazl akhond

islamic azad university mashhad medical sciences university

\section{Research Article}

Keywords: Nursing Faculty Practice, Faculty, Nursing

Posted Date: February 14th, 2022

DOI: https://doi.org/10.21203/rs.3.rs-1217916/v1

License: (c) (i) This work is licensed under a Creative Commons Attribution 4.0 International License.

Read Full License 


\section{Abstract}

Background: After the academization of nursing, obtaining, maintaining, and promoting of clinical credibility of nursing lecturers have always been a matter of challenge. Various studies have explored strategies for maintaining and promoting clinical credibility and a review study can integrate these results. This review study was conducted to evaluate strategies for maintaining and promoting clinical credibility of nursing lecturers.

Methods: This study was designed based on Noblit and Hare's qualitative meta-synthesis. Studies on clinical credibility of nursing lecturers were collected in the databases of Science Direct, PubMed, Scopus, and Eric from 2000 to 2021 . Finally, after reviewing the full texts and applying the evaluation criteria, 12 articles were included in this review. Each selected article was reviewed and key concepts extracted from each study were compared with other studies for final interpretation of clinical credibility of nursing lecturers and approaches for its improvement.

Results: We found that, clinical credibility of nursing lecturers has been interpreted as sufficient and appropriate experience and skills of lecturers in most of articles. Strategies for maintaining and promoting clinical credibility were organized into one main category and five subcategories, including clinical care, clinical links, transfer of skills, clinically orientated research, and motivational factors.

Conclusion: According to the results of the study, it is necessary to pay attention to the dimensions of being involved in care, establishing clinical communication, transferring skills, conducting clinical research and paying attention to motivational factors to develop and maintain the clinical credibility of nursing teachers.

\section{Introduction}

Education is considered as the core in the treasure of progress in societies. Therefore, the only way to achieve the desired level of learning is to provide education by professionals according to the needs of learners. Nursing is a complex and difficult occupation that, as an academic discipline, provides services to both healthy and diseased individuals ${ }^{[1]}$. The ultimate goal of educating nursing students is to provide patients with provincial care. Obviously, the quality of services provided to patients depends on the quality of nursing education and clinical validity of nursing lecturers ${ }^{[2]}$. Among academic disciplines, nursing is one of those in which clinical credibility of lecturers is of particular importance ${ }^{[3,4]}$. Clinical validity of nursing lecturers has different definitions, the first of which is that a lecturer must have sufficient and appropriate clinical experience and experience to teach students the necessary skills. Obviously, less experience and skills of a lecturer will result in less success of the teacher in teaching and educating students ${ }^{[5,6]}$. According to Elliott and Wall, clinical credibility of a nursing lecturer is that, while teaching students or learners theoretically, as he/she should be able to express sufficient information and skills practically with regard to the subject matter ${ }^{[7]}$. From the perspective of nursing students and lecturers, clinical credibility of a lecturer means taking care of a patient. This means that a nursing 
lecturer should educate students to be able to apply clinically for the patient what they have learned theoretically in the future ${ }^{[3]}$. According to Morgan, clinical credibility of nursing lecturers means that nursing educators and managers have different competencies in intensive care units. In addition, lecturers must be able to apply their theoretical information practically and enhance their clinical competencies ${ }^{[8]}$.

Studies indicate that most nursing lecturers spend 20 percent of their teaching hours practically for students. In this regard, a lecturer needs to have proper clinical skills and besides perfect scientific knowledge ${ }^{[6]}$. As declared by the WHO (1999), nurses should be employed from experienced people, and this important point should also be highlighted in teaching and education of nursing so that the lecturers should support students practically while teaching theoretically ${ }^{[9]}$. Webster believes that clinical credibility of nursing lecturers means that they must retain their information and knowledge through practice and experience so that the instructor should promote their scientific knowledge, as well as clinical skills, leading to education of better and more successful students ${ }^{[10]}$. Based on the findings obtained from the reviewed studies, it can be concluded that clinical credibility of nursing lecturers is more related to the practical experience and skills of instructors. Therefore, strategies should be adopted to improve or maintain the clinical credibility of the lecturers ${ }^{[11,12]}$. Various studies have addressed and explored strategies for maintaining and improving clinical credibility based on the experiences of clinical instructors, and conducting a review study can integrate results of such studies. Accordingly and given the importance of this issue, this meta-synthesis review aimed to examine strategies for maintaining and improving clinical credibility of nursing lecturers.

\section{Methods}

The present meta-synthesis study was designed based on Nobilt and Hare's qualitative meta-synthesis method ${ }^{[13]}$. After defining the research title, namely clinical credibility of nursing lecturers and ways of its maintaining and improving in the first stage, studies meeting the inclusion criteria were included in the second stage. To this end, qualitative studies on factors related to clinical credibility in nursing were evaluated in databases (Science Direct, Pub Med, Scopus, and Eric) during 2000-2019 using keywords of clinical credibility, clinical competency, nursing lecturers, and improving clinical credibility. Inclusion criteria were studies conducted between 2000 and 2019, conducted among nursing lecturers population, and those containing information such as the definition of clinical credibility, its role in nursing lecturers, and ways of improving clinical credibility; also, nursing lecturers' experiences of clinical practice must be mentioned in such studies. In the third stage, each selected study was carefully read out to identify key concepts. In the fourth stage, key concepts were extracted and put together to examine their interrelationships. In the fifth stage, key concepts extracted from each study were compared with those of other studies. Finally, common and relevant dimensions and concepts were extracted in the sixth stage. From the 126 studies extracted according to the inclusion and exclusion criteria, full texts were obtained from 12 selected articles in English. The process of searching and selecting articles is illustrated in Figure 1. 


\section{Results}

Based on a preliminary search of the abovementioned databases, 12 studies among qualitative investigations on clinical credibility of nursing lecturers and ways of its maintaining and improving during 2000-2019 were directly related to the research subject. The main results and specifications of the reviewed studies and the best studies selected based on close proximity to this study are systematically presented in Table 1.

Table 1

Characteristics of qualitative studies related to clinical credibility of nursing 


\begin{tabular}{|c|c|c|c|}
\hline $\begin{array}{l}\text { Author \& } \\
\text { year }\end{array}$ & Objective & Method & Key findings \\
\hline $\begin{array}{l}\text { Young, } \\
2012^{[14]}\end{array}$ & $\begin{array}{l}\text { A framework } \\
\text { for defining } \\
\text { and } \\
\text { developing the } \\
\text { clinical role of } \\
\text { lecturers in } \\
\text { mental health } \\
\text { nursing }\end{array}$ & $\begin{array}{l}\text { Qualitative/ } \\
\text { content } \\
\text { analysis }\end{array}$ & $\begin{array}{l}\text { Definition of the clinical role of lecturers in } \\
\text { mental health: Clinical practice and skills } \\
\text { are used in services provided to people } \\
\text { with mental disorders. This depends on } \\
\text { two important issues. First, possible } \\
\text { connections present between the } \\
\text { theoretical and practical issues. Second, } \\
\text { the way an instructor acts in the clinical } \\
\text { practice. This framework can be } \\
\text { categorized as: 1) Providing care for the } \\
\text { recipient, 2) Increasing making use of } \\
\text { experiences in the clinical setting, 3) } \\
\text { Learning new therapies, and 4) Applying } \\
\text { international guidelines in service delivery. } \\
\text { A very important similarity between } \\
\text { mental health lecturers and psychologists } \\
\text { is the application of common clinical } \\
\text { practice and skills. Maintaining and } \\
\text { improving clinical credibility is done in } \\
\text { harmony with the academic and clinical } \\
\text { roles of lecturers. }\end{array}$ \\
\hline $\begin{array}{l}\text { Heshmati- } \\
\text { Nabavi, } \\
2010^{[15]}\end{array}$ & $\begin{array}{l}\text { Understanding } \\
\text { of nursing } \\
\text { lecturers from } \\
\text { an effective } \\
\text { clinical } \\
\text { instructor }\end{array}$ & $\begin{array}{l}\text { Qualitative/ } \\
\text { grounded } \\
\text { theory }\end{array}$ & $\begin{array}{l}\text { An effective clinical instructor has the } \\
\text { clinical competencies of a good nurse. As } \\
\text { characteristics of an effective clinical } \\
\text { instructor, clinical skills are the result of } \\
\text { the institutionalization of knowledge. } \\
\text { Clinical competence turns nursing } \\
\text { educators into skilled person, and } \\
\text { provides clinical lecturers with "self- } \\
\text { confidence", which is transferred to } \\
\text { students thereby improving their learning. }\end{array}$ \\
\hline $\begin{array}{l}\text { McSharry, } \\
2010^{[16]}\end{array}$ & $\begin{array}{l}\text { The role of } \\
\text { nursing } \\
\text { lecturers in } \\
\text { clinical } \\
\text { performance } \\
\text { in the } \\
\text { Republic of } \\
\text { Ireland }\end{array}$ & $\begin{array}{l}\text { Qualitative/ } \\
\text { phenomenology }\end{array}$ & $\begin{array}{l}\text { Key points extracted from this study: } \\
\text { Paying attention and maintaining } \\
\text { lecturers' clinical credibility; the role of } \\
\text { lecturers as a source of support for staff. } \\
\text { Experienced and knowledgeable lecturers } \\
\text { can serve as a source for answering } \\
\text { questions or solving clinical problems of } \\
\text { staff. Besides teaching, a lecturer should } \\
\text { accompany students to the clinic, and } \\
\text { ultimately provide time for students to be } \\
\text { in the clinic with staff. There should also } \\
\text { be links and coordination between } \\
\text { education and clinical practice, and a well- } \\
\text { defined policy and program should be } \\
\text { present for the lecturer evaluation in the } \\
\text { clinical field. }\end{array}$ \\
\hline $\begin{array}{l}\text { Andrew, } \\
2011^{[17]}\end{array}$ & $\begin{array}{l}\text { The role of } \\
\text { practice in the } \\
\text { nursing } \\
\text { profession for } \\
\text { universities of }\end{array}$ & $\begin{array}{l}\text { Qualitative/ } \\
\text { action plan }\end{array}$ & $\begin{array}{l}\text { Practicing causes: 1) Evolution of learned } \\
\text { materials, 2) Practice will be permanent in } \\
\text { the clinical setting, 3) Practicing is a } \\
\text { factor to put theoretical information into } \\
\text { practice, 4) Practice should be done by } \\
\text { professionals or academics, and 5) It also }\end{array}$ \\
\hline
\end{tabular}


the $21^{\text {st }}$

century

provides research and research opportunities. Some nursing material may not be presented in the classroom, for which there is no other way than practical implementation, thus highlighting the importance of clinical skills in the nursing profession.

$\begin{array}{ll}\text { Meskell, } & \text { The clinical } \\ \text { 2009 [18] } & \text { role of nursing } \\ & \text { lecturers in } \\ & \text { Ireland: } \\ & \text { Perceptions of } \\ & \text { key groups on } \\ & \text { the role of } \\ & \text { nursing } \\ & \text { education }\end{array}$

Qualitative/ Mixed method exploratory

Ireland: the role of nursing ducation
Clinical credibility is an effective factor in linking theoretical and practical subject matters. As stated by an Irish student about clinical credibility, a lecturer could use this index to support them. Important points extracted in this study are: 1) Definition of clinical credibility of nursing lecturers (clear expression of clinical credibility, effects of this credibility, and changes due to this importance issue), 2) Involvement of lecturers in clinical practice and make them pay attention to challenges, 3) Providing necessary warnings about the importance of clinical credibility, 4) Applying clinical experiences to effective education, 5) Emphasizing and attention to clinical research.

Teaching process must be performed in the clinical setting so that students gain experience and practice.

Lecturers with clinical experience: Their explanations are clear and respond properly and rapidly to feedbacks by students. Novice lecturers: They cannot explain concepts well enough to students and lack real experience and understanding to explain for feedbacks by students.

Nursing education is changing. There is a high pressure today from the government and related organizations concerning clinical experience and practice for novice nursing lecturers. Nursing was initially taught practically, but it is today a combination of theory and practice, necessitating clinical skills and experience by the lecturer for better understanding of students.

In addition, the lecturer should teach students according to existing needs, which will require the lecturer to have a clinical work experience.

Important points extracted for maintaining clinical credibility include: 1) Providing lecturers with knowledge and information about the importance of clinical credibility, 2) Taking care by lecturers, 3) Attending 
clinical setting, 4) Transferring skills (transferability of theoretical to practical contents), and 5) Developing and learning more and better new skills.

$\begin{array}{lll}\text { Williams, } & \begin{array}{l}\text { Research on } \\ \text { the }\end{array} & \begin{array}{l}\text { Qualitative/ } \\ \text { Mixed method } \\ \text { understanding } \\ \text { and clinical } \\ \text { experience of } \\ \text { nursing } \\ \text { lecturers }\end{array}\end{array}$

The education policy is to be used more often in bedside and as clinical practice to facilitate learning. In this study, participants mentioned the importance of clinical credibility as a direct, planned, and supportive factor. According to lecturers' experience about their committed skills, clinical practice led to better understanding, better organization of subject matters, as well as a supportive factor in answering students' questions. It was concluded that lecturers with clinical experience were far more successful in teaching nursing and were able to properly link between theoretical and practical content and gain students' satisfaction. The study also found some barriers to teaching for lecturers who may pay less attention to clinical practice, including 1 ) less time, 2) high workload of lecturers, and 3) no support of clinical practice in education.

$\begin{array}{lll}\text { Hackett, } & \text { Performing } & \text { Qualitative/ } \\ \text { 2016] } & \begin{array}{l}\text { educational } \\ \text { and clinical } \\ \text { roles by } \\ \text { lecturers at } \\ \text { the clinic }\end{array} & \\ & \text { analysis }\end{array}$

The nursing education program has undergone revision and transformed into information transfer to clinical skills. Four key points drawn from this study include 1) task, 2) practice and experience, 3 ) clinical validation, and 4) students' experience. The beneficial effects of being in both education and clinical practice include better transfer of theory content to practice for students and maintaining current skills. However, an important challenge is that one has to manage both areas of his/her role, thereby possibly undergoing pressure.

\begin{tabular}{|c|c|c|}
\hline $\begin{array}{l}\text { De } \\
\text { Guzman, } \\
2007^{[23]}\end{array}$ & $\begin{array}{l}\text { A survey on } \\
\text { the viewpoints } \\
\text { of Philippine } \\
\text { nursing } \\
\text { students } \\
\text { about clinical } \\
\text { credibility of } \\
\text { nursing } \\
\text { lecturers }\end{array}$ & $\begin{array}{l}\text { Qualitative/ } \\
\text { content } \\
\text { analysis }\end{array}$ \\
\hline
\end{tabular}

All participants viewed positively about lecturers' clinical credibility. According to their viewpoints, the lecturer can use the clinical credibility to visualize and illustrate subject matters in the minds of students. In other words, clinical credibility is considered as a facilitating and effective factor in nursing students' learning, and also links nursing concepts and theories to clinical practice. According to participants, a lecturer with clinical experience and practice teaches and practices correspondingly, making students interested and, most importantly, creating positive feedback and confidence on the students' behalf. Hence, taking note 


\begin{tabular}{|c|c|c|c|}
\hline & & & $\begin{array}{l}\text { of this is one of the important principles } \\
\text { of nursing. }\end{array}$ \\
\hline $\begin{array}{l}\text { Carr, } 2007 \\
\text { [24] }\end{array}$ & $\begin{array}{l}\text { Changes in } \\
\text { nursing } \\
\text { education: } \\
\text { Being a } \\
\text { nursing } \\
\text { lecturer }\end{array}$ & $\begin{array}{l}\text { Qualitative/ } \\
\text { content } \\
\text { analysis }\end{array}$ & $\begin{array}{l}\text { Nursing lecturers still depend on adult } \\
\text { learning theory, empirical learning, and } \\
\text { skills training. Conventional learning is at } \\
\text { risk with these interpretations, making } \\
\text { lecturers pay less attention to clinical } \\
\text { practice, which requires taking relevant } \\
\text { measures. As with nurses, nursing } \\
\text { lecturers need to be more present in the } \\
\text { clinical setting, update themselves } \\
\text { clinically, and maintain and improve their } \\
\text { clinical skills. }\end{array}$ \\
\hline \multirow[t]{2}{*}{$\begin{array}{l}\text { Marshall, } \\
2013^{[25]}\end{array}$} & \multirow{2}{*}{$\begin{array}{l}\text { Clinical } \\
\text { credibility and } \\
\text { trust are key } \\
\text { features used } \\
\text { to identify } \\
\text { colleagues } \\
\text { seeking } \\
\text { information }\end{array}$} & \multirow[t]{2}{*}{$\begin{array}{l}\text { Qualitative/ } \\
\text { content } \\
\text { analysis }\end{array}$} & $\begin{array}{l}\text { - Clinical role: A person's privileged clinical } \\
\text { position is considered as a source of } \\
\text { information by colleagues. }\end{array}$ \\
\hline & & & $\begin{array}{l}\text { Reliability and trust: Privileged colleagues } \\
\text { in the clinical field received more attention } \\
\text { and appreciation. }\end{array}$ \\
\hline
\end{tabular}

Finally, key points and concepts were extracted from each reviewed study, similar concepts were compared and integrated, and then main dimensions and categories were extracted in relation to the improvement of clinical credibility of nursing lecturers (Table 2).

Table 2

Extracted dimensions and categories related to maintaining and improving clinical credibility of nursing lecturers 


\section{Conceptual Dimensions Components}

Maintaining and improving clinical

credibility
Hands- on care

- Having a clinical background and a professional specialty by lecturers

- Having a clinical role by lecturers

- Updating lecturers' clinical skills and information through frequent practices

\section{Clinical links}

- Creating learning culture among nursing staff and providing opportunities for learning and professional development among nurses by experienced lecturers

- Familiarity with the clinical setting and maintaining a good working relationship with the nursing staff

- Creating a sustainable learning environment

- Clinical/academic cooperation

- Visiting clinical settings
Transferability of skills - Exchange of clinical and scientific experiences between
nursing lecturers and experienced nurses

- Transfer of clinical and scientific experiences from experienced lecturers to novice professors

- Holding special skill-training courses for novice lecturers

Clinically orientated Research

- Increasing the benefits of clinically-related research more than educational research for developing the clinical environment and maintaining its relationship with lecturers.
- Doing teaching activities based on monitoring clinical environment changes.

- Providing an opportunity for nursing lecturers to scrutinize and express their concerns and problems about improving clinical credibility

Motivational factors
- Employing nursing lecturers interested in the clinical setting at universities

- Increasing ratings for working in clinical settings

- Providing facilities for practice and updating practical skills of nursing lecturers in clinical skills centers.

- Reduce workloads of nursing lecturers in educational settings and encouraging them to practice in clinical settings. 


\section{Discussion}

The important role of nursing lecturers in educating knowledgeable and skilled students is well known to everyone. The quality of service provided by nurses depends on a variety of factors, one of the most important of which is the role of lecturers and the quality of teaching ${ }^{[26]}$. Results of reviewed studies indicate that most nursing lecturers do not have much interaction with clinical experience and do not pay attention to their previous experiences in teaching related topics ${ }^{[27]}$. Nursing lecturers do not need to provide students with information in all clinical areas, but they can provide information to students depending on the needs of students and the area where future students will serve and care for patients. Clinical credibility and experiences of nursing lecturers can also be applied to further address practical issues of nursing, which in turn can be used to guarantee the quality of nursing care, indicating the high importance of clinical validity of nursing lecturers ${ }^{[28]}$.

There are various ways to maintain and improve clinical credibility of Iranian nursing lecturers. For example, methods applied in countries such as Ireland, Australia, and Canada, where nursing education has shifted to clinic- and hospital orientation rather than a university-orientated one ${ }^{[29]}$, can also be considered in our nursing curriculum to fill the gap between theoretical and practical materials. In addition, students will better understand the concepts and theories of nursing. Sayer argues that both lecturers and students should specifically spend courses in clinical practice, so that it can fill the gap between theoretical and practical nursing materials, and lecturers can concurrently review their skills, thereby improving the skills, if necessary ${ }^{[19]}$. According to the reviewed studies, lecturers with clinical credibility and backgrounds could better interact with students in clinical settings and to respond better to students' errors. A lecturer without proper and sufficient clinical credibility may not effectually be able to bridge the gap between the theories and the taught nursing subjects with what should be addressed in principle ${ }^{[27]}$.

Results of the reviewed studies reveal that the clinical credibility of nursing lecturers is not very high; therefore, it is important to provide conditions for improving and maintaining the clinical credibility of nursing lecturers. One of the ways to achieve this goal is to hold in-service classes and workshops as possible for lecturers and professors, so that they can keep up with state-of-the-art clinical practices while retaining their own skills. Another effective step is to revise student curricula, meaning that the concepts and theories contained in the textbooks should be based on practice, and the lecturer should teach the realities that students will encounter in clinical settings by considering such situations ${ }^{[30]}$. Nursing students can better learn nursing courses when they can use experienced, knowledgeable, and skilled lecturers in a specific area ${ }^{[31]}$.

Maslin conducted a study aiming at increasing clinical credibility of nursing lecturers and instructors in clinical practice, and reported that such issues as working lecturers in clinical practice, developing the educational setting, and researching in clinical situations can effectively help maintain and improve the clinical credibility ${ }^{[32]}$. According to Barrett, nursing lecturer's clinical credibility is a factor in better and 
more direct learning, development, and understanding of students; however, some educational and political factors preclude maintaining clinical credibility of lecturers. It has been reported that most lecturers do not use in their teaching profession the experiences and situations encountered in bedside to facilitate student learning. It is also not possible to employ active nursing lecturers in all fields, which also has an effect in failing to achieve this ideal goal. It is important to pay attention to nursing curricula for consideration of clinical credibility. Key and strategic points in this regard include paying attention to numbers of students in education, renovating the clinical role of lecturers, creating innovation and creativity, and developing clinical learning strategies ${ }^{[33]}$.

Another effective approach of maintaining and improving clinical credibility of lecturers is to establish policies for employing nursing professors. For instance, applicants with a minimum of clinical work experience should be selected when recruiting nursing lecturers and instructors. According to Nahas, an instructor should have at least 5 years of experience in clinical practice, be able to express their experiences to students, educate using new approaches such as role-playing, and ultimately provide an environment for better learning to be able to function properly using such approaches ${ }^{[12]}$. Ousey stated that lecturers are considered as a source of support for teaching and internships. Clinical credibility of nursing lecturers means taking care of patients, and its most important effect is that it leads to more focus of the lecturer during teaching and ultimately students can better understand nursing concepts and materials. Lecturers should engage students directly in the care process not merely observe the student, and should also evaluate students' performance and provide them with feedbacks ${ }^{[3]}$. The amounts of equipment and facilities at clinical skill rooms of nursing schools can also pave the ground for nursing lecturers to be inclined towards learning new clinical skills or updating the procedures they are dealing with depending on existing facilities. In this respect, financing and budget allocation to required equipment are influential in this important issue ${ }^{[34]}$.

Due to low numbers of lecturers and employees, the present lecturers often devote their time to research and teaching, hence, they may be less involved in bedside and do not have the opportunity for improving their clinical credibility and skills. Another study also stated that lecturers who are interested in their fields sought to improve their clinical skills and credibility more than those who consider nursing as their occupations. Thus, this should be taken into account when recruiting nursing lecturers to employ those interested in the nursing profession ${ }^{[2]}$. Also, it is worth considering the suggestion of lecturers about teaching some materials in the clinical environment and on patient's bedside because this method makes the lecturer seek new therapeutic techniques. Further reduction of the gap between theoretical and practical contents also helps to better learn and understand subject matters. Another approach for maintaining or improving the clinical credibility of lecturers is to provide them with evaluation policies and plans that can help assess their clinical credibility and experience. Also, courses and workshops should be held for lecturers who seem to need further retraining to familiarize them with the latest clinical practices while maintaining their own information ${ }^{[16]}$.

\section{Conclusion}


According to the above findings, it can be concluded that the clinical credibility of nursing lecturers plays a very important and prominent role in better transferability of nursing concepts, materials, and theories to students, as well as in improving the nursing care quality by future nurses. In addition to mastering theoretical topics, nursing lecturers must be able to link between theoretical and practical issues, prepare students for the critical nursing profession, and always seek to improve their practical information and skills. It is, therefore, necessary to consider the aspects of involvement in care, clinical links, transferability of skills, clinically-oriented research, and motivational factors in order to improve and maintain the clinical credibility of nursing lecturers.

\section{Declarations}

\section{Conflicts of interest}

The authors declare that they have no conflict of interest

\section{Conflicts of interest}

The authors declare that they have no conflict of interest

\section{Ethics approval and consent to participate:}

this article is A meta-synthesis study and In general, the meta-analysis study is exempt from ethics approval as the study authors will be collecting and synthesizing data from previous clinical trials in which informed consent has already been obtained by the trial investigators.

\section{Consent for publication:}

Not Applicable

\section{Availability of data and materials:}

All of the datasets generated and/or analysed during the current study are available in the article, this study is a meta-analysis study and all of the datasets during the current study are available in the main text.

\section{Competing interests:}

The authors declare that they have no Competing interests. 


\section{Funding:}

The authors declare that no funds, grants, or other support were received during the preparation of this manuscript.

\section{Authors' Contributions:}

I/we certify that I/we have participated sufficiently in the intellectual content, conception and design of this work or the analysis and interpretation of the data (when applicable), as well as the writing of the manuscript, to take public responsibility for it and have agreed to have my/our name listed as a contributor. I/we believe the manuscript represents valid work. Each author confirms they meet the criteria for authorship as established by the ICMJE. Neither this manuscript nor one with substantially similar content under my/our authorship has been published or is being considered for publication elsewhere, except as described in the covering letter. I/we certify that all the data collected during the study is presented in this manuscript and no data from the study has been or will be published separately.

\section{Acknowledgements:}

We give the rights to the corresponding author to make necessary changes as per the request of the journal, do the rest of the correspondence on our behalf and he/she will act as the guarantor for the manuscript on our behalf.All persons who have made substantial contributions to the work reported in the manuscript, but who are not contributors, are named in the Acknowledgment and have given me/us their written permission to be named. If $\mathrm{I} /$ we do not include an Acknowledgment that means $\mathrm{I} /$ we have not received substantial contributions from non-contributors and no contributor has been omitted.

\section{References}

1. Amouzeshi Z, Mohsenizadeh M, Amouzeshi A. Effect of teaching nursing process using integrated method (Concept map and advance organizer) on nursing students' clinical learning. Future of Medical Education Journal. 2015;5(1):68-71.

2. Heidarzadeh M, Izadi A, Rahmani A, Zamanzadeh V. Characteristics of efficient clinical teachers: nursing educators' and students' perspectives. Iranian Journal of Medical Education. 2012;11(7):70417.

3. Ousey K, Gallagher P. The clinical credibility of nurse educators: time the debate was put to rest. Nurse Education Today. 2010;30(7):662-5.

4. Gillespie $M$, McFetridge $B$. Nurse education-the role of the nurse teacher. Journal of Clinical Nursing. 2006;15(5):639-44.

5. Beigzadeh A, Rahimi M, Lashkari M, Haghdoost A, Seyed Askari S. A Survey on the Characteristics of an Effective Clinical Teacher from the Viewpoints of Nursing students at Kerman University of 
Medical Sciences. Iran Journal of Nursing. 2015;28(95):44-53.

6. Mohammadi MM, Parandin S. Effective clinical instructors from the perspective of students and clinical teachers in Kermanshah University of Medical Sciences in 2015. Development Strategies in Medical Education. 2015;2(1):38-46.

7. Elliott M, Wall N. Should nurse academics engage in clinical practice? Nurse Education Today. 2008;28(5):580-7.

8. Morgan A. Call yourself a nurse! Defending the clinical credibility of educators and managers in intensive care. Nursing in critical care. 2012;17(6):271-4.

9. Key E. Making a Difference: strengthening the nursing, midwifery and health visiting contribution to health and healthcare. AIMS Journal. 2000;11(4):21-2.

10. Landers MG. The theory-practice gap in nursing: the role of the nurse teacher. Journal of advanced nursing. 2000;32(6):1550-6.

11. Taheri A, Forghani S, Atapour S, Hasanzadeh A. The effective clinical teaching from faculty members' and rehabilitation students' point of view. Iranian Journal of Medical Education. 2012;11(9):1131-9.

12. Nahas VL. Maintaining clinical credibility as a nurse teacher in a postgraduate tertiary specialization program. Clinical nurse specialist. 2000;14(4):184-8.

13. Hoon C. Meta-synthesis of qualitative case studies: An approach to theory building. Organizational Research Methods. 2013;16(4):522-56.

14. Young N, Evans N, Bowring-Lossock E. The Practice Engagement Framework: a framework that assists the identification and development of the clinical role for lecturers in mental health nursing. The Journal of Mental Health Training, Education and Practice. 2012;7(1):42-6.

15. Heshmati-Nabavi F, Vanaki Z. Professional approach: The key feature of effective clinical educator in Iran. Nurse Education Today. 2010;30(2):163-8.

16. McSharry E, McGloin H, Frizzell AM, Winters-O'Donnell L. The role of the nurse lecturer in clinical practice in the Republic of Ireland. Nurse Education in Practice. 2010;10(4):189-95.

17. Andrew N, Robb Y. The duality of professional practice in nursing: Academics for the 21 st century. Nurse Education Today. 2011;31(5):429-33.

18. Meskell P, Murphy K, Shaw D. The clinical role of lecturers in nursing in Ireland: Perceptions from key stakeholder groups in nurse education on the role. Nurse Education Today. 2009;29(7):784-90.

19. Sayer L. Strategies used by experienced versus novice practice teachers to enact their role with community nurse students. Nurse education today. 2011;31(6):558-63.

20. Fisher MT. Exploring how nurse lecturers maintain clinical credibility. Nurse Education in Practice. 2005;5(1):21-9.

21. Williams A, Taylor C. An investigation of nurse educator's perceptions and experiences of undertaking clinical practice. Nurse Education Today. 2008;28(8):899-908. 
22. Hackett N, Harvey-Lloyd J, Rooke N. Performing dual roles in education and practice: Experiences of lecturers who also work as clinicians: a literature review and study. Nursing Management. 2016;23(3):31-7.

23. de Guzman AB, Ormita MJM, Palad CMC, Panganiban JK, Pestaño HO, Pristin MWP. Filipino nursing students' views of their clinical instructors' credibility. Nurse education today. 2007;27(6):529-33.

24. Carr G. Changes in nurse education: being a nurse teacher. Nurse Education Today. 2007;27(8):893-9.

25. Marshall AP, West SH, Aitken LM. Clinical credibility and trustworthiness are key characteristics used to identify colleagues from whom to seek information. Journal of Clinical Nursing. 2013;22(910):1424-33.

26. Kermansaravi F, Navidian A, Imani M. Nursing students' views toward quality of theoretical and clinical nursing education: A qualitative study. The Journal of Medical Education and Development. 2013;7(4):28-40.

27. Salminen L, Minna S, Sanna K, Jouko K, Helena L-K. The competence and the cooperation of nurse educators. Nurse education today. 2013;33(11):1376-81.

28. Manley K, Titchen A. Facilitation skills: the catalyst for increased effectiveness in consultant practice and clinical systems leadership. Educational Action Research. 2017;25(2):256-79.

29. Leonard L, McCutcheon K, Rogers KM. In touch to teach: Do nurse educators need to maintain or possess recent clinical practice to facilitate student learning? Nurse education in practice. 2016;16(1):148-51.

30. Bagheri $H$, Bazghaleh M. Clinical education and its related factors in nursing: A qualitative metasynthesis study. Journal of Nursing Education. 2016;4(4):26-39.

31. Shokohi M, Haghdoost A-A, Majdzade R, Reiani F. Identifying the Characteristics of Educational Influential Nurses: A Qualitative Study. Strides in Development of Medical Education. 2013;10(2).

32. Maslin-Prothero SE, Owen S. Enhancing your clinical links and credibility: the role of nurse lecturers and teachers in clinical practice. Nurse Education in Practice. 2001;1(4):189-95.

33. Barrett D. The clinical role of nurse lecturers: past, present, and future. Nurse Education Today. 2007;27(5):367-74.

34. Brennan A-M, Hutt R. The challenges and conflictsof facilitating learning in practice: the experiences of two clinical nurse educators. Nurse Education in Practice. 2001;1(4):181-8.

\section{Figures}




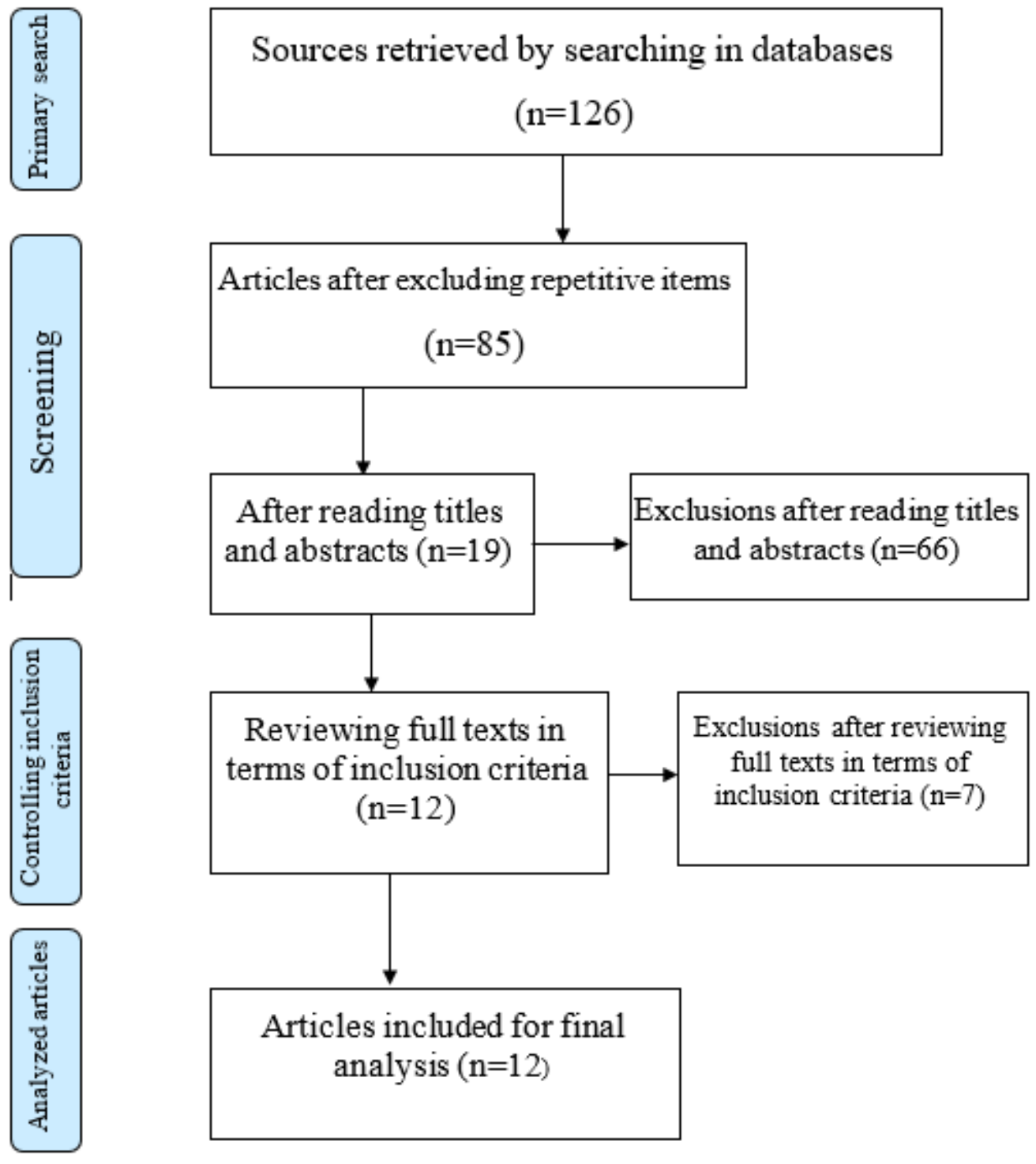

\section{Figure 1}

Preferred reporting items for the flow diagram of systematic reviews 